\title{
Quantitative analysis of the influence of synthetic fibres on plastic shrinkage cracking using digital image correlation
}

Bertelsen, I. M.G.; Ottosen, L. M.; Fischer, G.

Published in:

Construction and Building Materials

Link to article, DOI:

10.1016/j.conbuildmat.2018.11.268

Publication date:

2019

Document Version

Peer reviewed version

Link back to DTU Orbit

Citation (APA):

Bertelsen, I. M. G., Ottosen, L. M., \& Fischer, G. (2019). Quantitative analysis of the influence of synthetic fibres on plastic shrinkage cracking using digital image correlation. Construction and Building Materials, 199, 124-137. https://doi.org/10.1016/j.conbuildmat.2018.11.268

\section{General rights}

Copyright and moral rights for the publications made accessible in the public portal are retained by the authors and/or other copyright owners and it is a condition of accessing publications that users recognise and abide by the legal requirements associated with these rights.

- Users may download and print one copy of any publication from the public portal for the purpose of private study or research.

- You may not further distribute the material or use it for any profit-making activity or commercial gain

- You may freely distribute the URL identifying the publication in the public portal 

digital image correlation

I. M. G. Bertelsen ${ }^{a^{*}}$, L. M. Ottosen ${ }^{\text {a }}$, G. Fischer ${ }^{\mathrm{a}}$

${ }^{a}$ Department of Civil Engineering, Technical University of Denmark, Brovej 118, 2800 Kgs. Lyngby, Denmark

* Corresponding author. E-mail: imgber@byg.dtu.dk

\section{Abstract}

The plastic shrinkage cracking behaviour of restrained mortar overlays on a concrete substrate was studied with the aim of quantifying the influence of commercially available polypropylene (PP) fibres and recycled polyethylene (R-PE) fibres obtained from discarded fishing nets. The use of R-PE fibres was investigated with a view to creating a more eco-friendly construction material. The plastic shrinkage behaviour was evaluated on the basis of a non-contact 2D digital image correlation (DIC) technique that enables the automated detection of surface displacements and strains with high precision. Based on the DIC data, the degree of surface cracking was quantitatively analysed using a MATLAB post-processing procedure and presented in detailed histograms showing the crack width distribution of the entire specimen surface. Using this data, the effect of fibre reinforcement on crack control was objectively quantified and evaluated. The results indicate that while the addition of $2.0 \%$ of $\mathrm{R}-\mathrm{PE}$ is effective in controlling shrinkage cracking in the mortars, the commercial PP fibres perform better even at volume fractions as low as $0.1 \%$. These findings show that the recycled fibres can be used to reduce plastic shrinkage cracking behaviour compared to unreinforced materials, while a waste material is being reused, though, a much larger volume fraction of RPE fibres than of commercially available PP fibres is necessary to achieve a similar effect. 
Deformation of cementitious materials due to plastic shrinkage is one of the reasons for surface cracking occurring in concrete structures, especially when environmental factors create a high rate of water evaporation from the fresh material $[1,2]$. Concrete structures with internal or underlying restraints and a large surface area-to-volume ratio such as surface repairs, slabs, tunnel linings, etc. are especially vulnerable to plastic shrinkage cracking [3]. Combined with a high degree of mixing water evaporation, such restraints can cause tensile stresses within the cement-based composite that exceed the tensile strength of the plastic material, which causes surface cracking to appear in the composite $[4,5]$. The plastic shrinkage period of cement-based materials only lasts for a few hours, and depends on parameters such as binder type, geometry and environmental conditions [2].

Several studies have proposed methods for restrained plastic shrinkage testing in which a fresh mortar overlay is cast on top of a bottom-restraining concrete substrate or a rough underlay [6-13]. A test method previously developed by the authors was used in this study for addressing the crack formation in such bonded overlay-substrates by digital image correlation (DIC) [13]. In recent years, various types of imagebased techniques have been applied for the detection and analysis of plastic shrinkage-induced surface cracking, which is a great improvement compared to the more manual measuring techniques using optical microscopes to study the crack formation. The image-based techniques are valued for their high-precision, the non-contact optical analysis, which avoids all disturbance of the fresh cementitious material as well as human error [12,14-18]. Among these techniques, DIC is especially effective for monitoring surface strain and displacement fields, which enables automated crack detection and the ability to see the evolution of cracks over time. The application of a high-contrast surface pattern is required for tracking the surface displacements and strains by the DIC technique [19]. Nevertheless, so far very few studies on the shrinkage behaviour of fresh cement-based materials have used the DIC technique $[12,20-24]$. This could be due to the difficulty of applying a high-contrast surface pattern for the DIC monitoring due to bleeding water present on specimen surfaces $[22,24]$ and the sealing effect of most paint types, which reduces the evaporation rate. In [13] a diffusion open chalk-based paint type was applied for creation of a high-contrast 
speckle pattern for DIC and it was found not to influence the evaporation rate of mixing water from the fresh mortar surface.

The addition of randomly distributed low-modulus fibres of synthetic materials in cementitious composites is often used to control cracking caused by plastic shrinkage deformations $[1,2]$. These fibres are known to improve the strain capacity of the fresh mixture by providing bridging forces across the cracks so that many very fine cracks appear instead of fewer but larger cracks $[1,2,25]$. The efficiency of synthetic fibres for controlling plastic shrinkage cracking has been widely studied in the literature and has been shown to depend on several variables, such as the added fibre volume fraction, the fibre material $[9,17,26]$, fibre shape and geometry $[3,4,9,17,27-29]$, and their mechanical properties $[9,30]$. The literature largely agrees that the best performance in reducing plastic shrinkage cracks results from finer and longer fibres (high aspect ratio) with good fibre-to-matrix bonding properties $[3,9]$. It has been shown that by adding PP or PVA fibres with a fine diameter in volume fractions as low as $0.1-0.2 \%$ to the mixture, it is possible to achieve an apparently crack-free surface $[3,9,11,25,27]$. However, Najm \& Balaguru [31] report that polyolefin macro fibres also perform well when added in volume fractions of $2 \%$. Not only commercially available virgin fibres have been shown to be effective in controlling plastic shrinkage cracking, but also various types of recycled fibres [4,28,29,32-34]. The use of recycled synthetic fibres has generally gained recognition in the construction industry due to their broad availability, low price and sustainability aspects $[35,36]$. In this study, recycled fibres obtained from discarded fishing nets were used for controlling plastic shrinkage cracking of restrained mortar overlays. Lost or otherwise discarded fishing nets is a major concern for the vulnerable marine environment and can cause severe damage to fish, sea birds and marine mammals if they continue to drift [37]. Besides being a threat to marine life, the nets are often difficult to transport, dispose of, and occupy high volumes at landfill sites. Fishing nets are nowadays made of synthetic materials such as PE, PP and nylon with fibre-shapes comparable to those of synthetic fibres used in cement-based materials. The performance of recycled nylon fibres from discarded fishing nets as fibre reinforcement in cementitious mortar composites was studied by Spadea et al. and Orasutthikul et al. for improving mechanical properties such as flexural strength and toughness and obtained promising results 
$[38,39]$. Likewise, the R-PE fibres investigated in the present study were also expected to positively influence the cracking behaviour induced by plastic shrinkage. Borg et al. [28] studied reprocessed macro fibres from waste PET bottles in volume fractions of $0.5-1.5 \%$ to control plastic shrinkage cracking, following the method in ASTM C1579. On the basis of the reduction in the average crack width, they found that deformed and long fibres performed better in controlling plastic shrinkage cracking than short and straight fibres. Kim et al. [4] also investigated reprocessed PET macro fibres of various shapes and geometries (twisted, crimped, embossed) in volume fractions of $0.1-1.0 \%$, and found no significant difference in the performance of the three fibre shapes. All three fibre shapes successfully reduced the total crack area when added in fractions of at least 0.5\%. Pešić et al. [29] used straight HDPE macro fibres from mixed post-consumer waste in volume fractions of $0.4-1.25 \%$. They achieved a reduction in crack width of $76-84 \%$ with $1.25 \%$ fibres added to the concrete mixture.

\subsection{Research concept and significance}

The aim of the present paper is to describe how a 2D-DIC technique recently proposed in [13] has been applied for the evaluation of the plastic shrinkage behaviour of free and restrained mortar overlays with addition of two types of low-modulus synthetic fibres. The DIC technique was used to monitor in-plane surface displacements and strains from $\mathrm{t}=1-25 \mathrm{~h}$ after casting. This enabled an automated post-processing procedure for the evaluation of the degree of surface cracking, quantified as crack width distribution and evolution in surface cracking, which gives a more detailed understanding of the plastic shrinkage behaviour than traditional approaches. This approach was used to objectively quantify and compare the influence of adding commercially available PP fibres and R-PE obtained from discarded fishing nets for the control of plastic shrinkage cracking in restrained mortar overlays.

\section{Experimental programme}

\subsection{Materials}


101 tests, a concrete substrate; see Table 1 for the basic raw material properties of the mortar overlay. When 102 fibres were added to the mixture, they replaced equivalent amounts of sand, which is the reason for the 103 varying proportions of sand in the mixture.

104

Table1. Raw materials for mortar mixture

\begin{tabular}{llll}
\hline Material & Type & Quantity & Proportions \\
& & {$\left[\mathrm{kg} / \mathrm{m}^{3}\right]$} & {$[\mathrm{c}: \mathrm{s}: \mathrm{w}]$} \\
\hline Cement & Portland Cement (type CEM I 52.5 N) & 700 & 1.0 \\
Fine aggregate & Sea sand (0-4 mm) & $980-1032$ & $1.40-1.47$ \\
Water & Tap water & 350 & 0.5 \\
\hline
\end{tabular}

\subsubsection{Fibres}

Two types of fibres were investigated for the control of shrinkage cracking: PP fibres of the type Fibrin

Fiberflex from PP Nordica, a fibre type commonly used to control plastic shrinkage cracking; and R-PE fibres obtained from discarded fishing nets. The R-PE fibres were provided by the Danish recycling company, Plastix $\mathrm{A} / \mathrm{S}$, and their properties are shown in Table 2. Variations in length, diameter and mechanical properties were found in the R-PE fibres due to an "uncontrolled" cutting operation and differences in origin. Prior to using the fibres, the fibres were cleaned in tap water to remove impurities such as sand and other residues from the fishing operation. For more information about the recycled fibre properties, see a previous study by the authors [40]. The fibre volume fractions in the mortar overlays investigated were 0.2 , 


\begin{tabular}{|c|c|c|c|c|c|c|}
\hline Material & Image & Fibre type & $\begin{array}{l}\text { Density } \\
{\left[\mathrm{g} / \mathrm{cm}^{3}\right]}\end{array}$ & $\begin{array}{l}\text { Diameter } \\
{[\mu \mathrm{m}]}\end{array}$ & $\begin{array}{l}\text { Length } \\
{[\mathrm{mm}]}\end{array}$ & $\begin{array}{l}\text { Fibre fractions } \\
\text { [vol\%] }\end{array}$ \\
\hline $\mathrm{PP}$ & & Monofilament & 0.91 & 19.5 & 12 & $0.1,0.2$ \\
\hline R-PE & & Monofilament & 0.95 & $280 \pm 30$ & $15 \pm 9 \mathrm{~mm}$ & $0.2,0.5,1.0,2.0$ \\
\hline
\end{tabular}

\subsubsection{Mixing procedure for mortar specimens}

The mixing procedure was carried out in a Hobart-type paddle mixer, where sand and cement were first dry-mixed for 2 min before water was gradually added to the mixture. "Time zero" ( $t=0 \mathrm{~min}$ ) was defined as the time when water was added to the dry mixture of sand and cement. Finally, the fibres were added to the mixture under continuous mixing (at $\mathrm{t}=3 \mathrm{~min}$ ) and mixed for another $5 \mathrm{~min}$. Specimens for both free and restrained shrinkage tests were cast by applying the fresh mortar into the respective moulds. The mortar surface was finished using a smooth steel trowel under continuous vibration at $60 \mathrm{~Hz}$ for up to 1 min on a vibration table. The total casting process took approx. 15 min from the start of wet-mixing (completed at $\mathrm{t}=15 \mathrm{~min}$ ). The fibre contents used did not result in any problems during mixing or casting, and no balling effect was encountered. The workability of the fresh mortar mixtures was determined using the flow table test in accordance with UNI/EN 1015-3 (1999). The fresh mortar was introduced in two layers into a lightly lubricated steel mould with a conical shape measuring $40 \times(75-65) \mathrm{mm}\left(\mathrm{h} \times \mathrm{d}_{\mathrm{i}, \text { bottom }-} \mathrm{d}_{\mathrm{i}, \text { top }}\right)$. The 


\subsection{Shrinkage tests}

137 Seven test series including free and restrained shrinkage tests of mortar mixtures with the addition of PP 138 fibres, R-PE fibres or no fibres (reference) were carried out and the components are shown in Fig. 1. See 139 also [13]. The restrained shrinkage test was carried out by pouring a fresh mortar overlay with dimensions 140 of $420 \times 95 \times 10 \mathrm{~mm}$ on top of an existing and cured concrete substrate produced in accordance with 141 UNI/EN 1339 (2003) with a desired roughness. The geometry and mixture design of the mortar overlay was 142 designed to have limited bleeding water and promote surface cracking in the restrained reference mortar. 143 The surface of the concrete substrate was roughened using a fine needle hammer to a depth of about 1 $144 \mathrm{~mm}$ to create an even restraint for the fresh mortar overlay. The substrate dimensions were $418 \pm 0.3 \mathrm{~mm}$ $145 \times 93.5 \pm 0.2 \mathrm{~mm} \times 49.6 \pm 0.2 \mathrm{~mm}$, so the substrates could fit into plywood moulds measuring $420 \times 95 \times 60$ $146 \mathrm{~mm}$. The compressive strength of the substrates was found to $35.5 \pm 6 \mathrm{MPa}$ (tested in accordance with 147 UNI/EN 12390-3 (2012) on $50 \mathrm{~mm} \times 100 \mathrm{~mm}$ cylinders) and the dry density to $2.180 \mathrm{~kg} / \mathrm{m}^{3}$. The concrete 148 substrates were wetted right before the fresh mortar overlay was applied.

149 The free shrinkage behaviour was measured on mortar specimens with the dimensions $420 \times 95 \times 10 \mathrm{~mm}$. 150 This geometry is the same as the mortar overlay used in the restrained shrinkage tests. Three replicates of 151 both free and restrained specimens were tested in each test series. In the experiment, the x-direction was 152 defined as being parallel to the longer side of the specimens $(420 \mathrm{~mm})$ and the $y$-direction parallel to the 153 shorter side of the specimens $(95 \mathrm{~mm})$.

Plan view: Shrinkage moulds

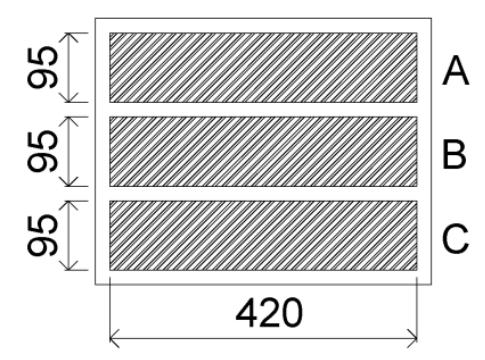

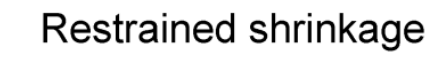

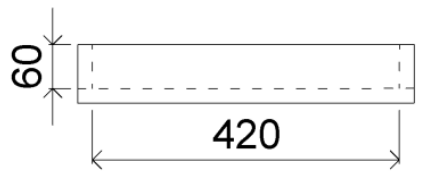

\section{Free shrinkage}

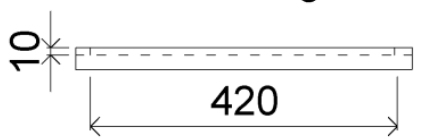

Restrained mortar overlay

Restraining concrete substrate

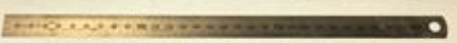

Free mortar specimen 
Fig. 1. a) Geometry of moulds for free and restrained shrinkage tests; b) Restrained mortar overlay on top of concrete substrate after demoulding; concrete substrate; and free shrinkage specimen. Three replicates of each test series were tested and labeled A, B, and C.

After casting $(t=15 \mathrm{~min})$, the specimens were kept in laboratory conditions $\left(20 \pm 3{ }^{\circ} \mathrm{C}\right)$, where they were left to rest for $30 \mathrm{~min}$. Limited plastic shrinkage was expected during this period due to the non-aggressive air temperature surrounding the specimens. Chalk-based spray paints were used for the creation of a highcontrast surface pattern in the period of $t=45-55 \mathrm{~min}$, consisting of a base of white chalk-based paint and a speckle pattern of black chalk-based paint, which has been shown not to influence the water evaporation rate from the fresh mortar [13]. The accuracy of the DIC computation mainly depends on the quality of the black speckle pattern, in which a consistent size and distribution of speckles is essential [19]. At $t=55 \mathrm{~min}$, the specimens were transferred to a climate-controlled chamber.

\subsubsection{Environmental conditions in climate-controlled chamber}

The shrinkage tests took place inside a climate-controlled chamber within the period of $t=1-25 \mathrm{~h}$. The test setup constructed for the shrinkage tests is shown in Fig. 2. Inside the chamber, a temperature of $32.0 \pm 1.5$ ${ }^{\circ} \mathrm{C}$ and a relative humidity of $33.5 \% \pm 5 \%$ were maintained during each test series, an environment chosen based on the recommendations in the ASTM standard C1579 (2013). The relative humidity was maintained by a dehumidifier. A wind flow in the range of $3.9-4.5 \mathrm{~m} / \mathrm{s}$ over the surface of the specimens parallel to the x-direction was applied using electric tangential fans that were placed in front of the specimens to ensure a constant wind flow. The wind speed was within the range as reported in other studies on plastic shrinkage cracking $[25,41]$ and was chosen to ensure that surface cracking appeared on the restrained reference specimens. 
Front view:

Shrinkage test setup

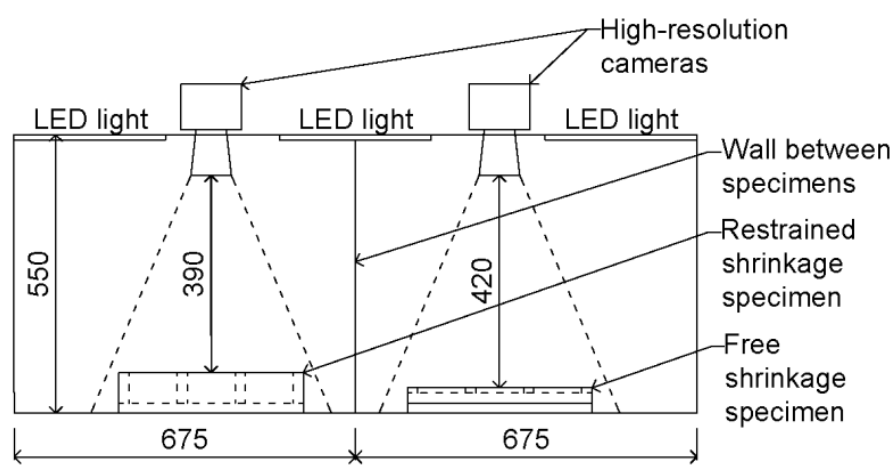

Side view:

Shrinkage test setup

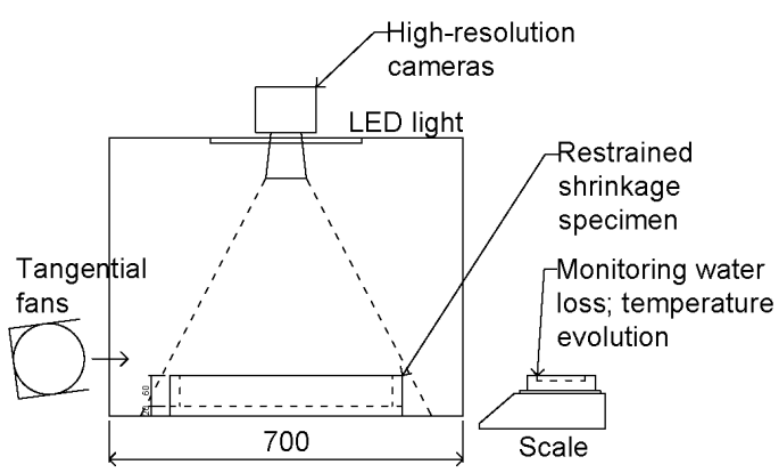

177

Fig. 2. The plastic shrinkage test setup using a 2D image acquisition system placed inside a climatecontrolled chamber.

\subsubsection{Monitoring of the shrinkage deformations by DIC}

The test setup shown in Fig. 2 consisted of two optical cameras with wide-angle lenses and a resolution of $7360 \times 4912$ pixels. The cameras were fixed parallel to the specimen surfaces capturing in-plane strains and displacements occurring on the specimen surface. The distance from the specimen surface to camera lenses was $390 \mathrm{~mm}$ for the restrained shrinkage specimens and $420 \mathrm{~mm}$ for the free shrinkage specimens. This difference resulted in slightly different pixel lengths for the two types of specimens $(0.087 \mathrm{~mm} / \mathrm{pixel}$ for the free shrinkage specimens and $0.080 \mathrm{~mm} /$ pixel for the restrained shrinkage specimens), but this small difference did not affect the accuracy of the deformation measurements. A constant light source was ensured by placing three LED panels at the top of the test setup.

For the DIC analysis, the software GOM Correlate Professional 2016 was used. The first image captured at $t$ $=1 \mathrm{~h}$ was defined as the undeformed image (reference stage), and subsequent images were taken at time intervals of 15 min until $t=25 \mathrm{~h}$. Each series of images was first modified in ImageJ to improve contrast and brightness prior to being imported to the DIC software. A region of interest (ROI) was defined in the DIC software for each specimen and was virtually meshed into a grid with overlapping subset elements with a (facet) size of $20 \times 20$ pixels and a centre distance of 15 pixels between each subset. The spacing between two points in the virtual grid is 15 pixels, which is equal to $1.305 \mathrm{~mm}$ for the free shrinkage specimens and 
$1.2 \mathrm{~mm}$ for the restrained shrinkage specimens. This geometry corresponds well with the applied high-

198 contrast surface pattern and the recommendations suggested by Sutton et al. [19].

199

200

\section{Results}

\section{$201 \quad 3.1 \quad$ Restrained shrinkage behaviour analysed using DIC}

202 The plastic shrinkage behaviour of the restrained mortar overlays with addition of PP or R-PE fibres was 203 tested in the period of $t=1-25 \mathrm{~h}$. At the end of each test series ( $t=25 \mathrm{~h})$, visible surface cracking had 204 appeared on some of the specimen types. The displacement and strain fields on the specimen surface were 205 calculated by the DIC software as the average value in each subset element. The strain fields are useful for 206 a visual representation of the surface cracking; see Fig. 3 and Fig. 4 where the in-plane strain fields on the 207 specimen surfaces in the $\mathrm{x}$-direction and $\mathrm{y}$-direction, respectively, are shown for all the specimens tested. 208 The figures clearly demonstrate the ability of the DIC technique to detect areas with increased strain, i.e. 209 position of surface cracks $[8,12,42]$. When analysing the strain fields by DIC, it was observed that the cracks 210 primarily appeared in the $x$-direction. This was because of the specimen geometry and wind flow parallel to 211 the $\mathrm{x}$-direction, so the focus was kept on displacements occurring in the $\mathrm{x}$-direction when quantifying the 212 degree of surface cracking (this is more thoroughly discussed in [13]). 
Specimen A
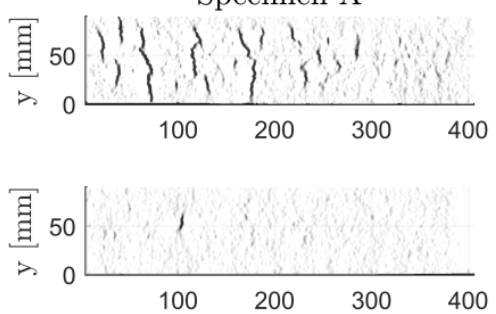

祃 50
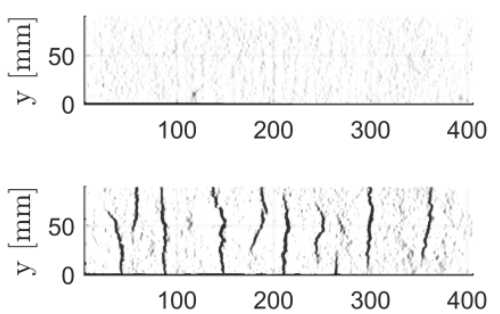

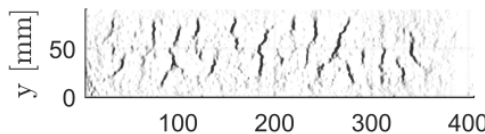
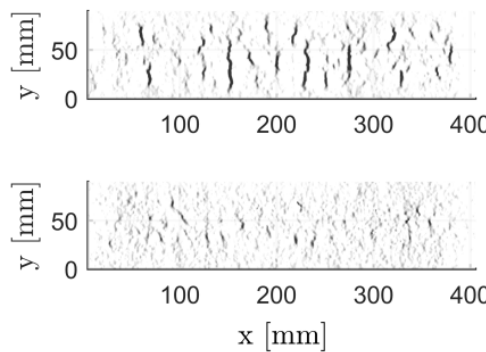

Specimen B
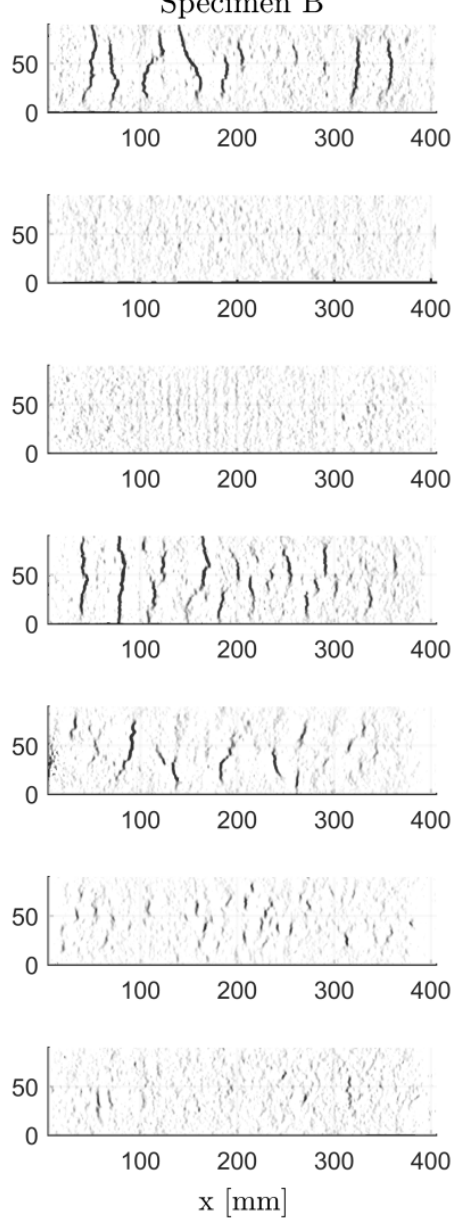

Specimen C
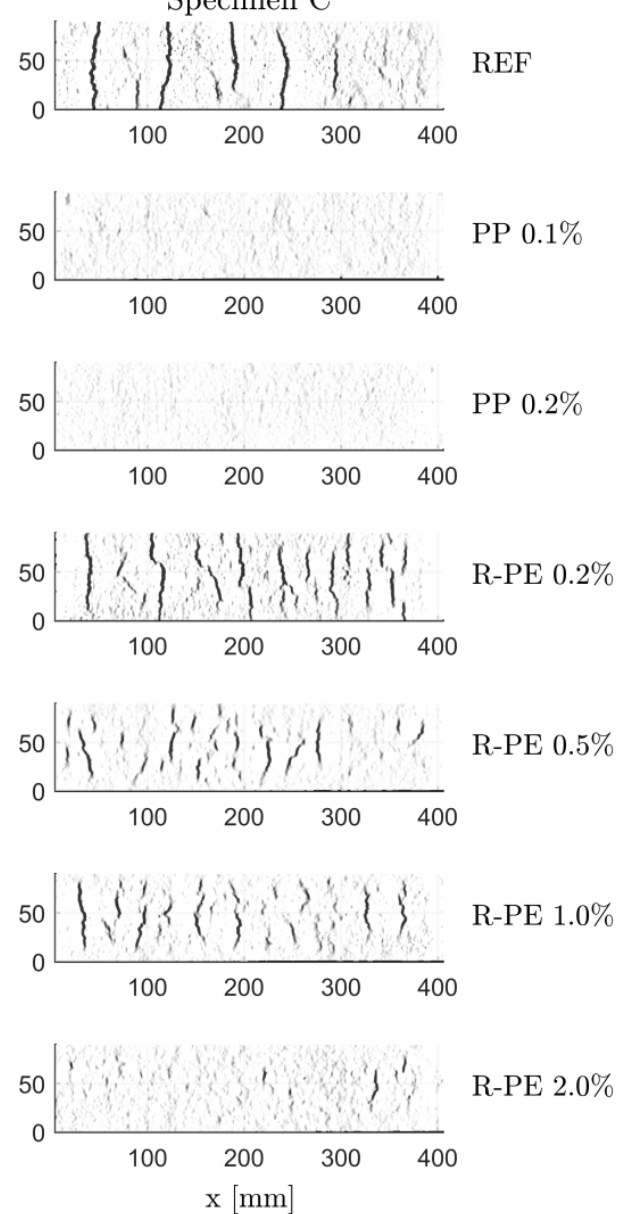

R-PE $2.0 \%$

Fig. 3. Strain fields parallel to the x-directions on the specimen surfaces. Plastic shrinkage-induced cracks are visually represented by peaks in the strain data represented with a black colour. White colour represents $\varepsilon_{\mathrm{x}}=0 \%$; Black colour represents $\varepsilon_{\mathrm{x}}=5 \%$. 

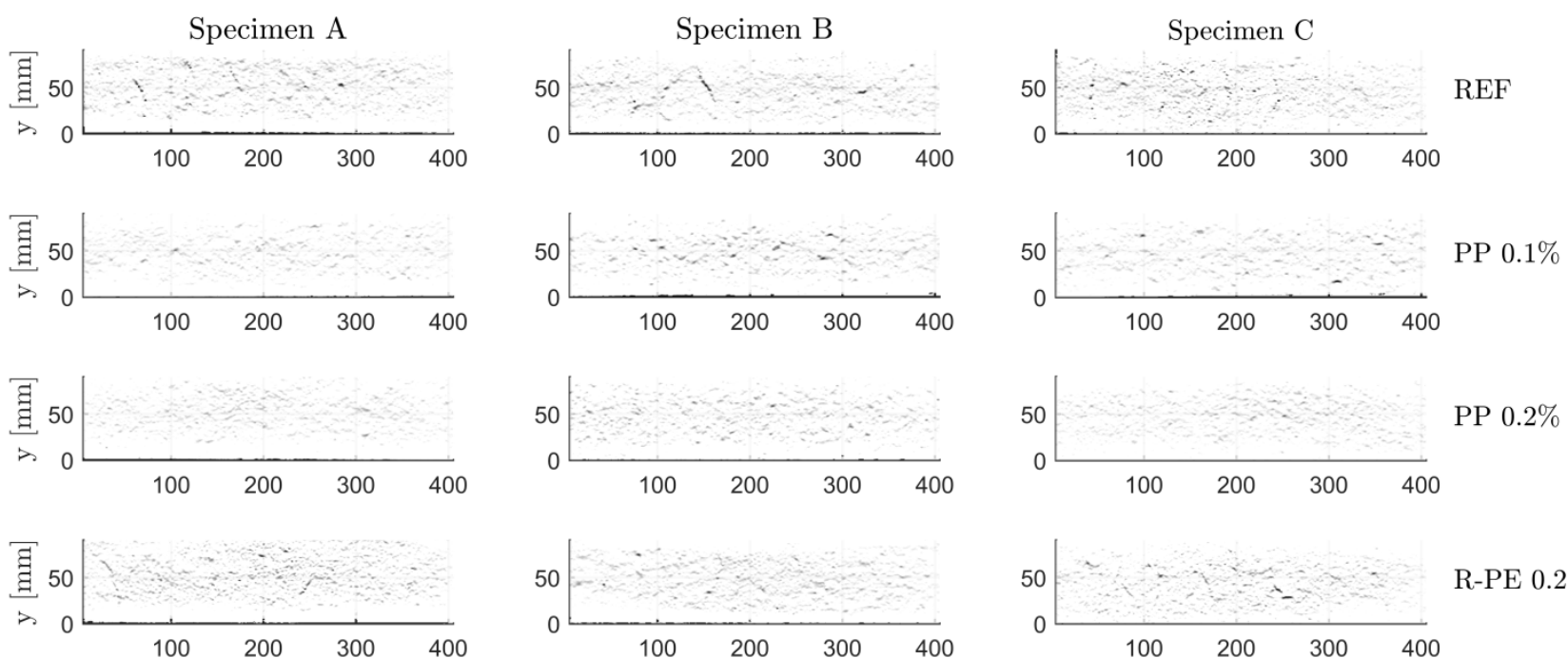

R-PE $0.2 \%$
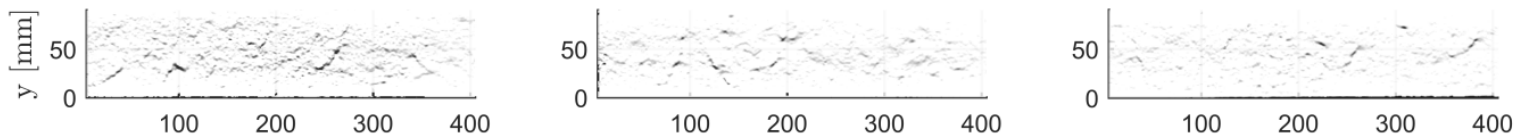

R-PE $0.5 \%$
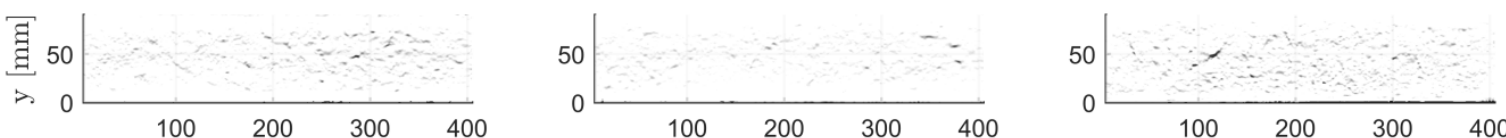

R-PE $1.0 \%$
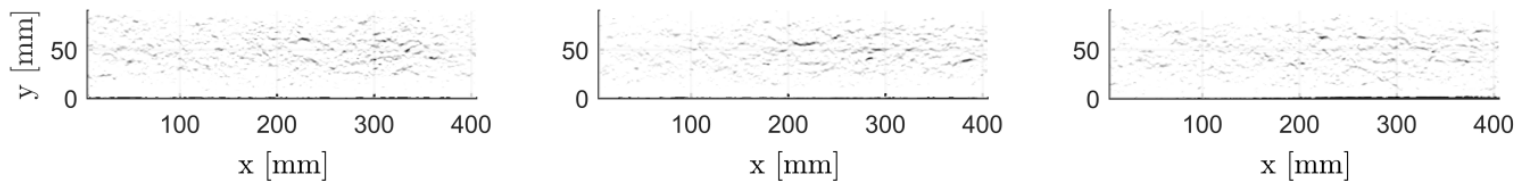

R-PE $2.0 \%$

221 Fig. 4. Strain fields parallel to the y-directions on the specimen surfaces. Plastic shrinkage-induced cracks are visually represented by peaks in the strain data represented with a black colour. White colour represents $\varepsilon_{y}=0 \%$; Black colour represents $\varepsilon_{\mathrm{y}}=5 \%$

Even from this simple visual inspection of surface strains, it is clear that the addition of fibres influences the cracking behaviour. As expected, the commercially available PP fibres performed well in controlling the 227 plastic shrinkage cracks. The R-PE fibres were also effective in controlling the surface cracking, though, as 228 anticipated, much larger fibre volume fractions were needed to obtain effects similar to PP fibres. However, Fig. 3 and 4 only give a visual illustration of the surface cracking; the results with respect to the quantitative degree of surface cracking will be given and explained in the following sections.

\subsubsection{Computation of crack parameters}


To obtain a quantitative measure of the degree of surface cracking in the restrained mortar overlay, a post-

processing procedure developed in MATLAB was used to compute crack parameters such as crack width, crack area, crack location and crack width distribution for the entire surface area based on the DIC data [13]. For each specimen, the DIC data was interpolated onto a rectangular grid with a point-to-point distance of $0.25 \mathrm{~mm}$. This enabled a section-wise analysis of each separate section $\left(n_{i, s e c}\right)$ parallel to the axis. Since the displacement mainly occurred in the x-direction, only the results for this direction are shown, which is considered a good approximation of the actual crack widths. This approach resulted in approximately 380 sections parallel to the $x$-direction for each specimen, which was considered sufficient for ensuring a high precision and quality of the crack width analysis.

242 The strain data is a numerical approximation to partial derivatives of the displacement, thus displacement 243 gaps are illustrated as local extrema in strain, i.e. surface cracks [8,42]. The crack widths in the $x$-direction 244 were determined based on sudden gaps in the displacement data along each separate section $\left(n_{i, s e c}\right)$ and were calculated as the increase in displacement between the minimum and maximum coordinate on each side of the displacement gap. This is represented by a blue and a red circle in Fig. 5-8b indicating respectively the displacement and strain along a selected section, A-A and B-B. To distinguish the actual cracks from less abrupt changes in surface displacement, it was relevant to define a criterion for the equivalent strain along a displacement gap. This was defined as a strain threshold value, $K_{0}$, considered to be the average strain value along a displacement gap, which made it less sensitive to noise rather than simply requiring an individual strain value to be above a threshold. In earlier work [13], the strain threshold 252 limit was defined as $K_{0}=20.0 \mathrm{~mm} / \mathrm{m}=2 \%$, chosen in agreement with microscopy observations, such that a 253 crack is a local interval where the average tensile strain along the displacement gap is larger than $K_{0}$, i.e.

$$
\varepsilon_{i, x, \text { avg. }}>K_{0} \Rightarrow \text { "Surface crack" }
$$

254 On this basis, it was possible to synthesize a digital reproduction of the crack patterns including crack width, 255 crack length, crack area and crack location. A similar approach for quantification of the cracked surface area 256 based on DIC data and a defined strain threshold value has been used before in studies of drying shrinkage $257 \quad[8,43]$. 
Examples on how the DIC data was used to compute these displacement gaps, i.e. surface cracks, are given

for different time stages for specimen REF (B) in Fig. 5-7 and for specimen PP 0.2\% (B) in Fig. 8. The figures are illustrating: a) the in-plane surface displacement by DIC data, b) a section view going through the centreline of the specimen showing the strain and displacement along the selected sections including crack widths for each displacement gap, and c) the crack pattern synthesized by the post-processing approach. Fig. 5-7 represents the reference specimen with no addition of fibres, REF (B), at different time stages (at $t$ $=2.0 \mathrm{~h}, \mathrm{t}=2.5 \mathrm{~h}$, and $\mathrm{t}=25 \mathrm{~h}$ ) to illustrate the evolution in surface cracking over time. At $\mathrm{t}=2.0 \mathrm{~h}$, there were 5 cracks along Section A-A with crack widths of $44 \mu \mathrm{m}, 75 \mu \mathrm{m}, 29 \mu \mathrm{m}, 156 \mu \mathrm{m}$ and $314 \mu \mathrm{m}$. At t $=2.5$ $\mathrm{h}$, in addition to the initiation of additional cracks, these 5 cracks had increased in width to $255 \mu \mathrm{m}, 46 \mu \mathrm{m}$, $291 \mu \mathrm{m}, 259 \mu \mathrm{m}$ and $394 \mu \mathrm{m}$, respectively. But between $\mathrm{t}=2.5 \mathrm{~h}$ and $\mathrm{t}=25 \mathrm{~h}$ only small increments in crack widths were observed. Fig. 8 shows the specimen with $0.2 \%$ of PP (B) at $t=25 \mathrm{~h}$ to illustrate the ability of the synthetic fibres to distribute the displacement, i.e. increase the strain capacity, across the restrained overlay so that very few and fine cracks appear compared to the reference specimen.

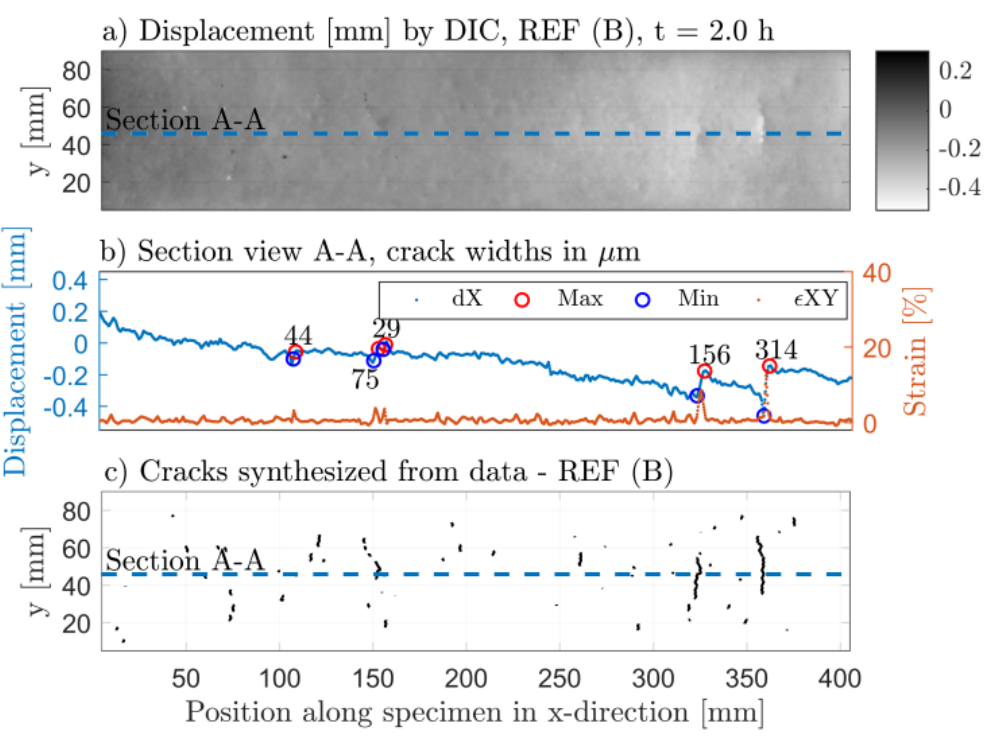

Fig. 5. Restrained specimen, REF (B), at $t=2.0 \mathrm{~h}$. a) Surface displacement in the $x$-direction by DIC data; b) Section A-A going through the centerline of the specimen showing the strain and displacement along the section; and c) the crack pattern synthesized from data by the post-processing approach. 

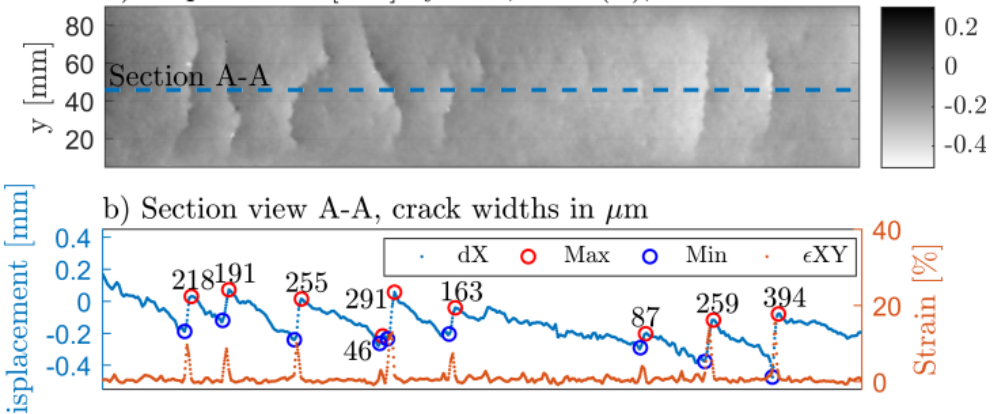

คำ

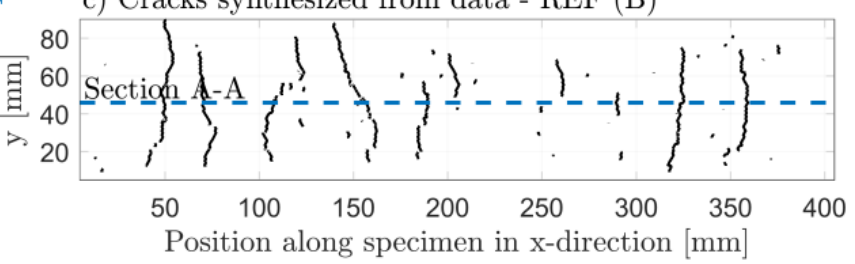

276 Fig. 6. Restrained specimen, $\operatorname{REF}(B)$, at $t=2.5 \mathrm{~h}$.

a) Displacement $[\mathrm{mm}]$ by DIC, $\mathrm{REF}(\mathrm{B}), \mathrm{t}=25 \mathrm{~h}$
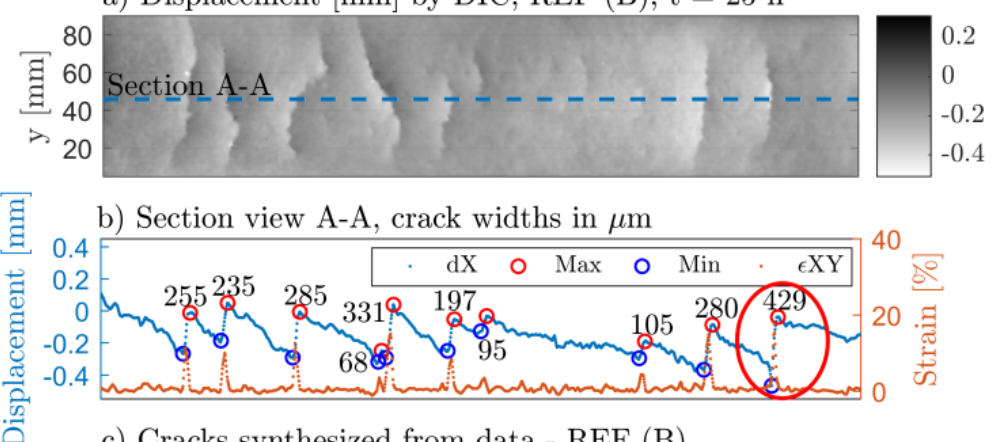

零

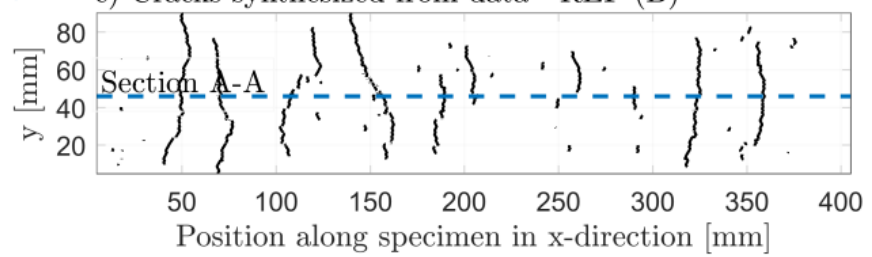

278 Fig. 7. Restrained specimen, REF (B), at $t=25 \mathrm{~h}$.

a) Displacement $[\mathrm{mm}]$ by DIC, PP $0.2 \%(\mathrm{~B}), \mathrm{t}=25 \mathrm{~h}$
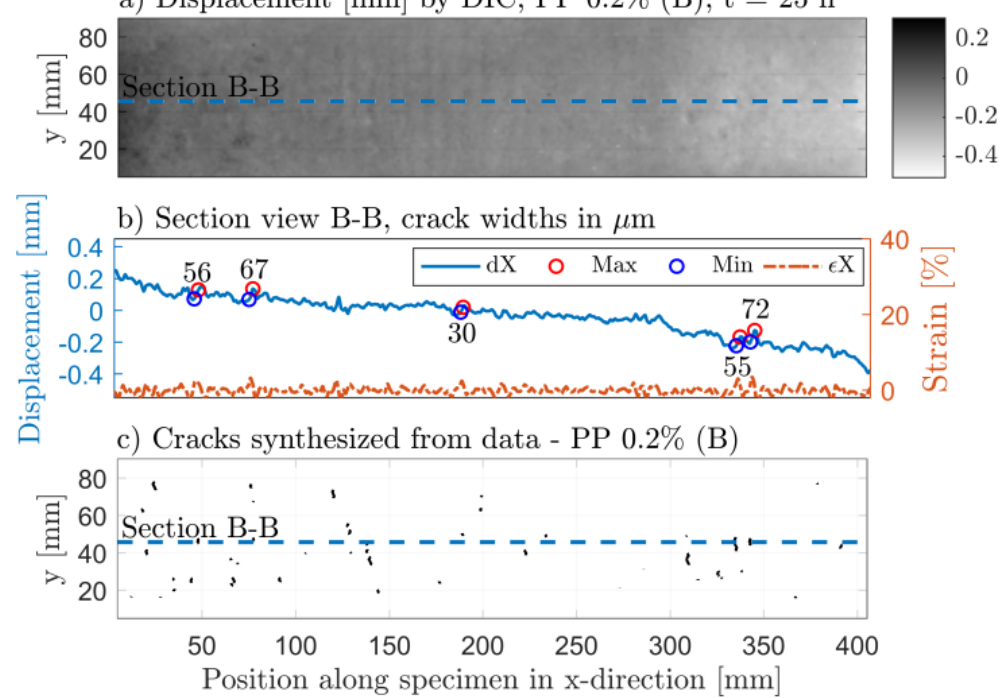
Fig. 8. Restrained specimen, PP $0.2 \%(B)$, at $t=25 \mathrm{~h}$.

When a crack occurs on the specimen surface, the texture of the representative subsets is modified, which in some cases can lead to local interpolation errors in the displacement field in close vicinity to a crack resulting in an overestimation of the crack width. These local errors in the DIC data were observed for a few of the identified cracks, but for the majority, a strong correlation between the crack width (vertical displacement gap calculated as the difference between the minimum and maximum value on each side of the crack) and microscopy measurements were observed. In the given example of specimen REF (B) at $t=$ 25 h shown in Fig. 7b, such an error is identified for the crack marked inside the red circle (crack width calculated to $429 \mu \mathrm{m}$ ). On the left side of the actual displacement gap (crack), an additional drop in displacement is detected in the digital facet, but when comparing it with microscopy observations this additional drop is not physically present, and, therefore, considered as a local error. Other studies suggested determining the crack widths by interpolating the values of the "uncracked" displacement field along the section in between the cracks [8]. Since the surface deformations in the present study were monitored starting from when the material was still in the fresh, plastic state, and since the overlay was evenly bottom-restrained, the displacement field in between the actual cracks is not completely linear as seen in Fig. 5-8c, thus this method was not considered to give a sufficiently precise estimation of the crack width. As shown in Section 3.2, the degree of cracking is presented as crack width distributions (CWD) over the entire specimen surface. Despite the very few local errors in the DIC data, which were found to result in an overestimation of the maximum observed crack width, these local anomalies in the digital facets are not significant for the crack width distribution as they involve only a small number of pixels, i.e. crack length and crack area.

\subsection{Quantification of surface cracking}

304 The degree of surface cracking due to plastic shrinkage has in the literature most commonly been evaluated based on basic crack parameters such as the mean and maximum crack width, mean and maximum crack 
length and the total crack area on the specimen surface $[4,9]$. As the DIC technique enables a precise analysis of the crack widths over the entire specimen surface, it allows an objective quantification, which is essential for the comparison of the restrained plastic shrinkage behaviour of different types of mixture designs. In this study, the crack widths ( $w_{i, s e c}$ ) along each of the approximately 380 individual sections $\left(n_{i, s e c}\right)$ of the interpolated grid on each specimen were calculated based on the post-processing procedure described in the previous sections (see also [13]). The total crack area was calculated by summing up all crack widths along each section. Based on the post-processing procedure, basic crack parameters, such as the mean crack width, the maximum crack width, and the total crack area could also be objectively computed and are shown for each specimen ( 7 types with 3 replicates) in Table 3. The crack reduction ratio (CRR) for the total crack area (TCA) and maximum crack width (MCW), respectively, which were calculated in accordance with the ASTM standard C1579 (2013) are also given in Table 3. From these results it is observed that the addition of fibres in most cases had a positive influence on the degree of surface cracking, however, these discrete values don't provide any information about the distribution of crack 319 widths.

Table 3. Basic crack parameters from restrained shrinkage test series at $t=25 \mathrm{~h}$. Three replicates of each specimen type $(\mathrm{A}-\mathrm{C}) . \mathrm{MCW}=$ Maximum crack width; $\mathrm{TCA}=$ Total crack area; $\mathrm{CRR}=$ Crack reduction ratio

\begin{tabular}{|c|c|c|c|c|c|c|c|c|c|c|c|c|}
\hline \multirow{3}{*}{ Fibre } & Fraction & \multicolumn{3}{|c|}{ Mean crack width } & \multicolumn{3}{|c|}{ Maximum crack width } & \multicolumn{3}{|c|}{ Total crack area } & \multirow{2}{*}{$\begin{array}{l}\text { CRR for } \\
\text { MCW [-] }\end{array}$} & \multirow{2}{*}{$\begin{array}{l}\text { CRR for } \\
\text { TCA [-] }\end{array}$} \\
\hline & \multirow[t]{2}{*}{ [vol\%] } & \multicolumn{3}{|c|}{$[\mu \mathrm{m}]$} & \multicolumn{3}{|c|}{$[\mu \mathrm{m}]$} & \multicolumn{3}{|c|}{$\left[\mathrm{mm}^{2}\right]$} & & \\
\hline & & A & B & C & A & B & C & A & B & C & Mean & Mean \\
\hline REF & 0 & 168 & 176 & 216 & 574 & 521 & 893 & 111 & 122 & 168 & 0.00 & 0.00 \\
\hline PP & 0.1 & 117 & 65 & 54 & 261 & 134 & 97 & 4.4 & 3.1 & 1.9 & 0.75 & 0.98 \\
\hline PP & 0.2 & 74 & 63 & 46 & 132 & 152 & 52 & 0.5 & 6.3 & 0.1 & 0.83 & 0.98 \\
\hline R-PE & 0.2 & 215 & 171 & 189 & 687 & 659 & 593 & 206 & 144 & 207 & 0.02 & -0.39 \\
\hline R-PE & 0.5 & 137 & 137 & 139 & 362 & 682 & 388 & 112 & 63 & 89 & 0.28 & 0.34 \\
\hline
\end{tabular}




\begin{tabular}{llllllllllllll}
\hline R-PE & 1.0 & 140 & 87 & 155 & 405 & 219 & 570 & 94 & 26 & 117 & 0.40 & 0.41 \\
R-PE & 2.0 & 78 & 74 & 92 & 225 & 182 & 286 & 23.1 & 14.4 & 24 & 0.65 & 0.85 \\
\hline
\end{tabular}

323

Another more comprehensive way of quantifying the surface cracking is based on the crack width distribution (CWD) over the surface area as it was also done in other studies on cracking of cementitious materials $[42,44,45]$. The CWD appears to give a more quantitative result for the degree of surface cracking, because the basic crack parameters don't give any information about the number of cracks with specific crack widths that are present on the specimen surface. The CWD is relevant since a few wide cracks can be more deteriorative to a steel reinforced concrete structure than a large number of fine cracks due to the penetration of salts and other aggressive agents [46]. In the present study, the CWD was illustrated by the relation between the crack widths and the total crack length or the total crack area within each bin interval, thus revealing the amount of cracks within each specific crack width interval at $t=25 \mathrm{~h}$, see Fig. 9 and Fig. 10, respectively. As explained in Section 3.1.1, some of the widest cracks could be a result of local interpolation errors in the DIC data, nevertheless, we have decided to include all identified crack widths in the CWD. First, it is observed that the shape of the CWD showed similar tendency for each type of replicates, thus some variations in the size of the crack widths appear. Secondly, some of the widest cracks are only present in small quantities, i.e. cracks with this crack width are only identified along a few of the sections on the specimen surface and does only reveal when representing the CWD as the total crack area of each bin interval as shown in Fig. 10. Comparing the CWD with the results given in Table 3, it is clear that the CWD provide a much more detailed result of the degree of surface cracking. The specimens with the most severe surface cracking were the specimens with addition of $0.2 \%$ R-PE and the REF specimens, where maximum crack widths of approximately 500-900 $\mu \mathrm{m}$ were observed. It was expected that the addition of $0.2 \%$ R-PE fibres would have had a small influence of the cracking behaviour, but this small amount of R-PE fibres did not improve the performance with regard to the surface cracking. When considering the maximum and mean crack widths, the $0.2 \%$ R-PE and REF specimens behaved similarly. Besides the fibre addition of $0.2 \%$ R-PE, which was considered too low for this fibre type, the figures illustrate how fewer 
wide cracks appeared when adding fibres to the mixture. The PP fibres showed a superior ability to control

348 the plastic shrinkage cracks even at volume fractions as low as $0.1 \%$, but these fibres were also produced 349 for controlling plastic shrinkage cracking in cementitious materials, thus this good result was expected. The 350 R-PE fibres, when added in volume fractions of $0.5-2.0 \%$ also had an effect on the surface cracking. The 351 addition of $0.5-1.0 \%$ R-PE fibres resulted in a significant reduction in cracks with a crack width larger than $352300 \mu \mathrm{m}$, but results indicated that this amount of fibres did not lead to a desirable reduction in surface 353 cracking. Considering the specimens with 2.0\% R-PE fibres, a reduction similar to the specimens with PP 354 fibres was almost achieved and no cracks with a crack width larger than $300 \mu \mathrm{m}$ were found on any of the 355 specimen's surface.
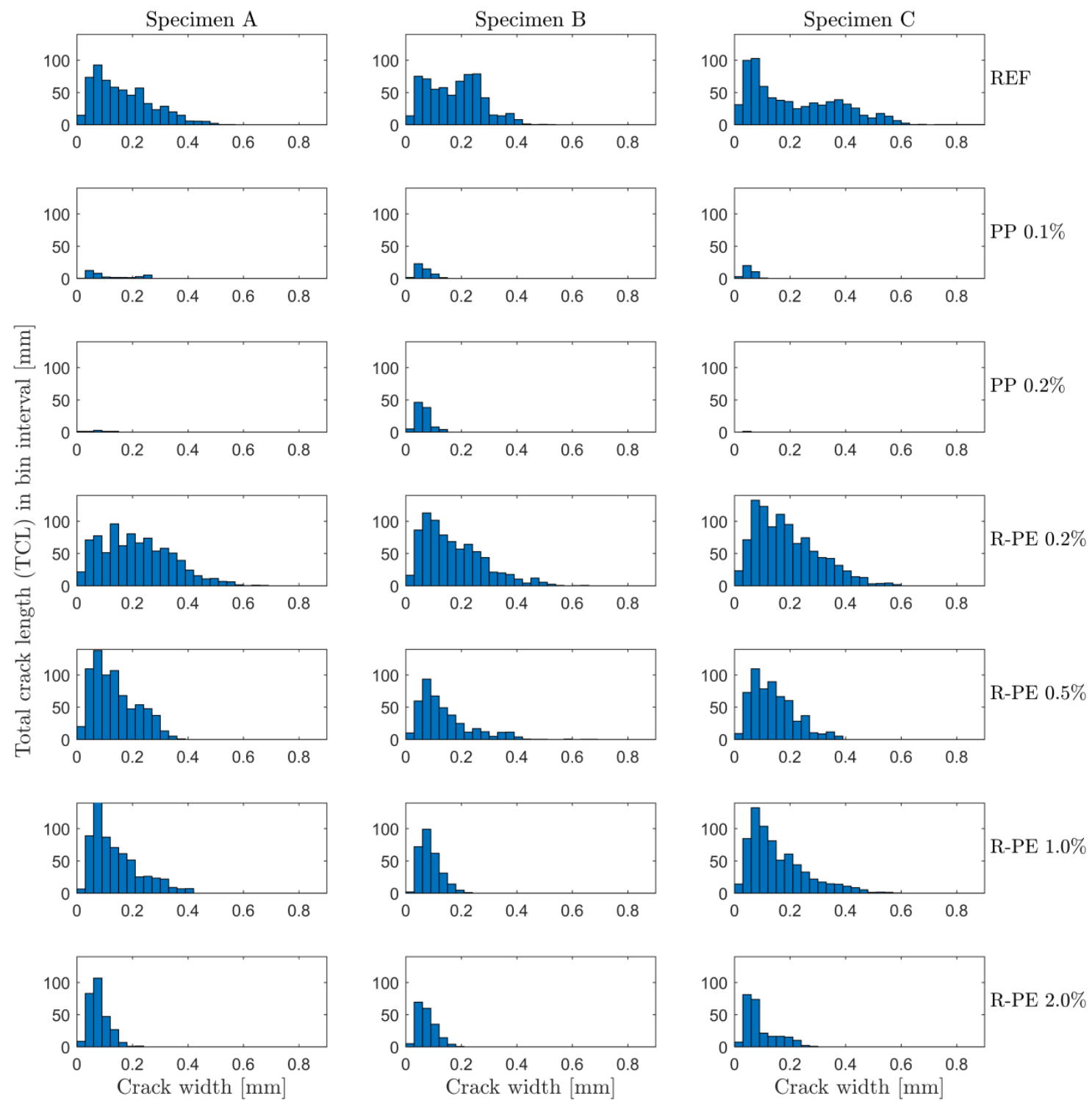
Fig. 9. Histograms of the relation between the total crack length [mm] in each bin interval and the crack width
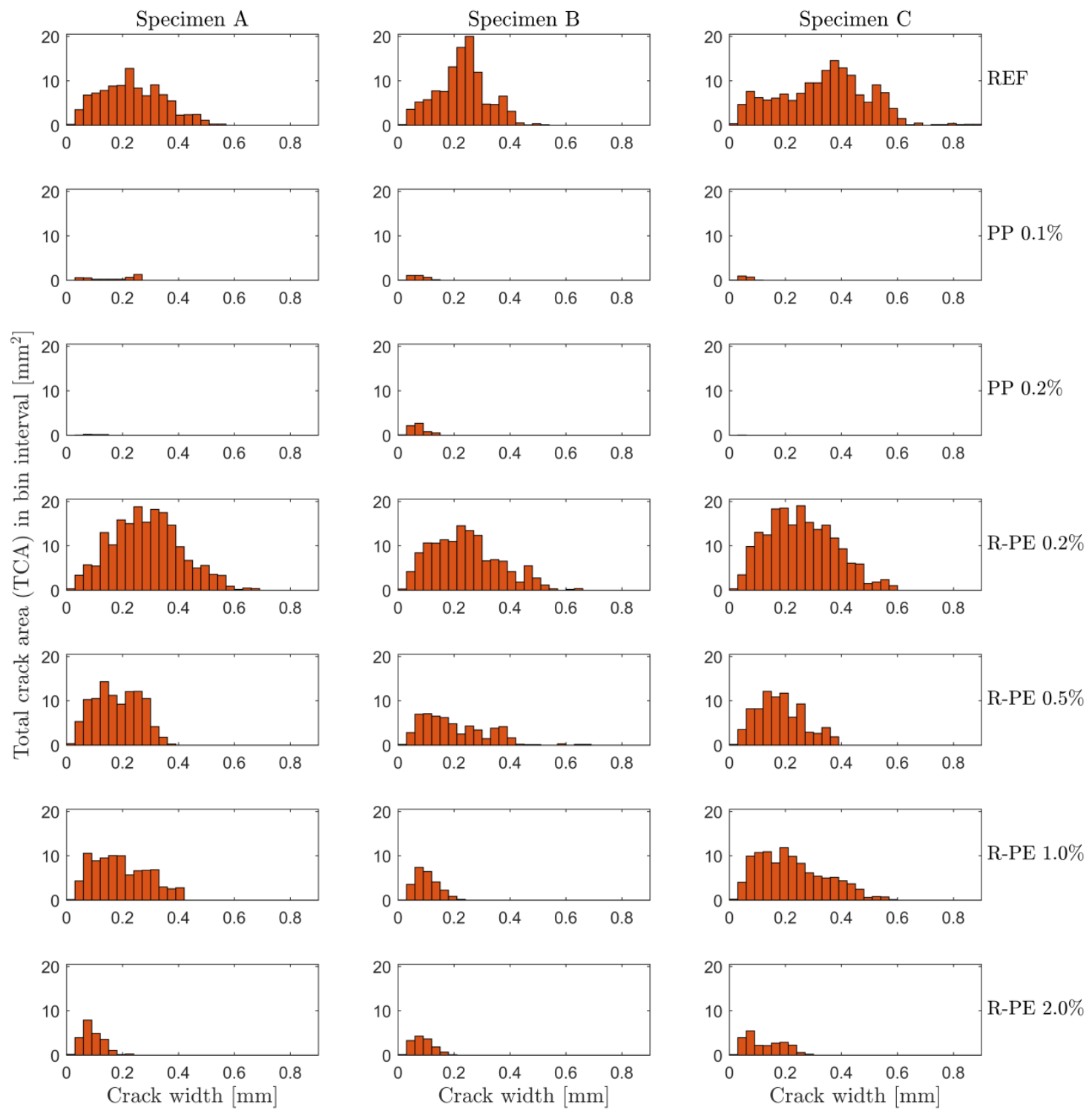

Fig. 10. Histograms of the relation between the total crack area $\left[\mathrm{mm}^{2}\right]$ in each bin interval and the crack width distribution (CWD) over the entire specimen surface at $t=25 \mathrm{~h}$ 
Fig. 9-10 and Table 3 represent different ways of evaluating the degree of surface cracking, with Fig. 9-10

being more quantitative than the basic crack parameters in Table 3. However, both evaluation strategies show that the most severe cracking appeared in the $0.2 \%$ R-PE specimens and the REF specimens, both with regard to crack widths and total crack area. The R-PE fibres performed well when added in volume fractions of $2.0 \%$ and showed varying effect when added in volume fractions below $1.0 \%$. This relatively high volume fraction for R-PE fibres to achieve their best results compared to PP fibres corresponds well with what other studies have found using macro fibres for controlling plastic shrinkage cracking, although the $2.0 \%$ of R-PE were in the high end of the range of necessary fractions of macro fibre found by $[4,28,29,31]$. The R-PE fibres used in this study were straight in shape and had a diameter of $280 \pm 30 \mu \mathrm{m}$, which is approximately 15 times the diameter of the commercial PP fibres. The R-PE fibres were not reprocessed, but simply cut down to monofilament fibres, which were possible because of the origin of the fibres, as the lines in the fishing nets consisted of several monofilament fibres, which were braided or twisted, thus relatively easy to separate from each other when processing the fibres from the discarded material. Previous studies have found that a deformed fibre shape is beneficial in controlling plastic shrinkage cracking because of the improved fibre-to-matrix bonding $[4,28]$, which could also explain the need for a volume fraction of $2.0 \%$ of R-PE fibres. Regarding the performance of the fine PP fibres, similar behaviour has been observed in several other studies on the use of PP fibres for the control of plastic shrinkage cracking $[3,9,25,27,30,31]$.

\subsubsection{Evolution in surface cracking}

The shrinkage specimens were monitored at intervals of $15 \mathrm{~min}$ during the entire test period starting at $\mathrm{t}=$ $1 \mathrm{~h}(\mathrm{t}=1 \mathrm{~h}$ as reference stage, i.e. cracking $=0)$, so the CWD at different time stages could be computed as a measure of the evolution in surface cracking. The evolution in CWD is of interest as it would reveal if the fibres had any influence on the time of initiation and stabilization of surface cracking. Histograms at selected time stages showing the evolution in CWD in relation to the total crack area (TCA) in each bin interval are given in Fig. 11. Additionally, the evolution in surface cracking is also represented by the 
393 first few hours after casting, the evolution in the total crack area is shown for the time period of $\mathrm{t}=1-5 \mathrm{~h}$ in 394 Fig. 12. Mean values of three replicates (A-C) are given for each specimen type.

395

396
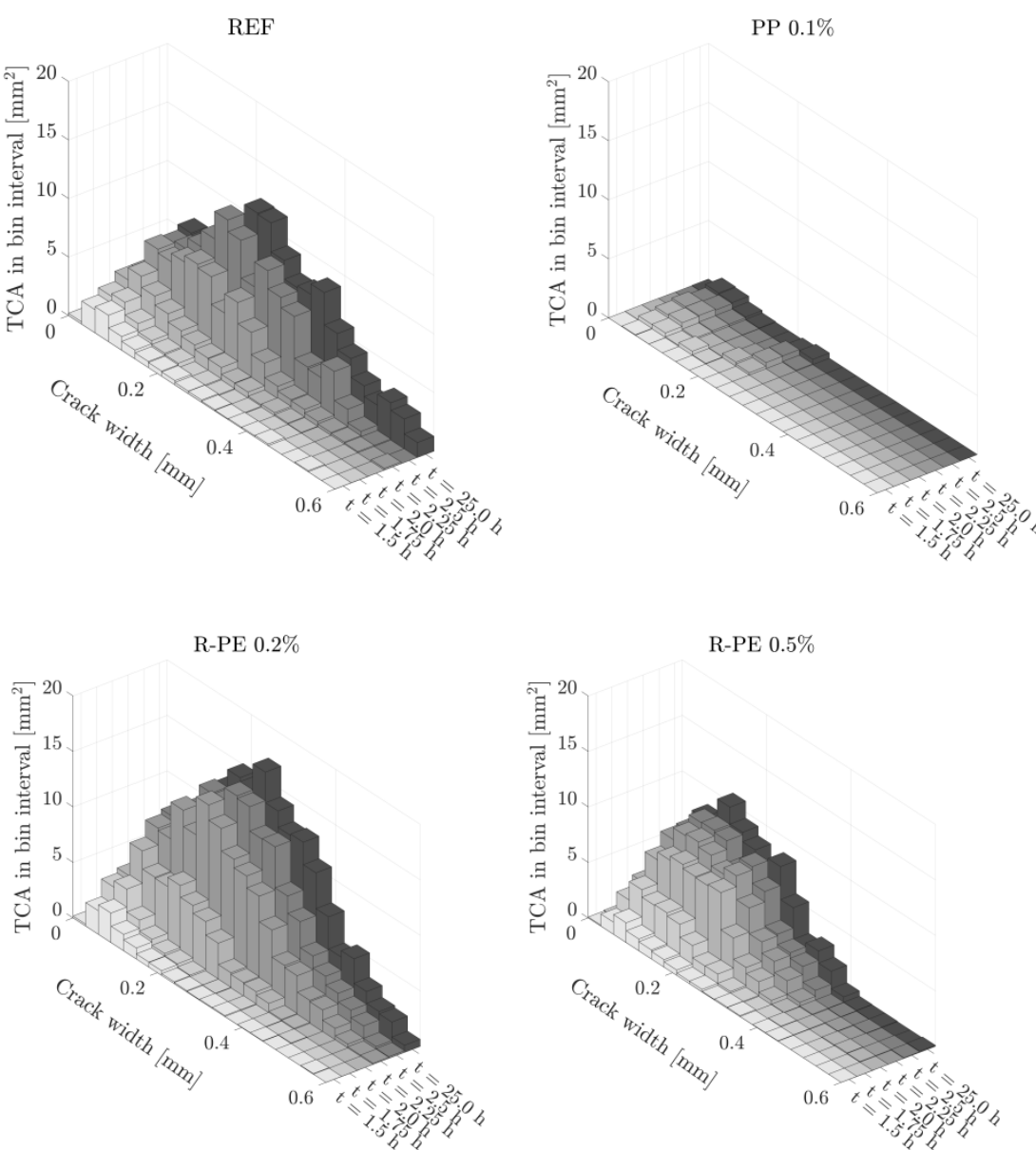

R-PE $2.0 \%$

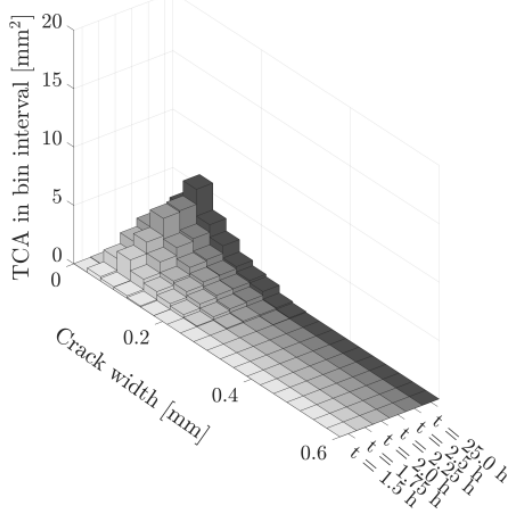

$$
\begin{aligned}
\mathrm{t} & =1.5 \mathrm{~h} \\
\mathrm{t} & =1.75 \mathrm{~h} \\
\mathrm{t} & =2.0 \mathrm{~h} \\
\mathrm{t} & =2.25 \mathrm{~h} \\
\mathrm{t} & =2.5 \mathrm{~h} \\
\mathrm{t} & =25.0 \mathrm{~h}
\end{aligned}
$$

R-PE $0.5 \%$
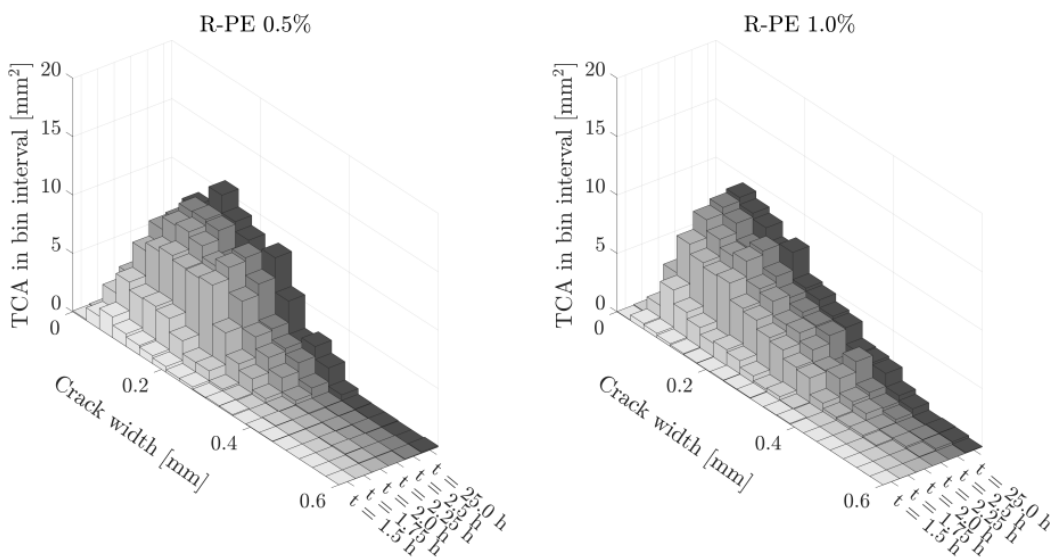
400

401

402

403

404

405

406

407

408

409

410

411

Fig. 11. Histograms of the relation between the total crack area $\left[\mathrm{mm}^{2}\right]$ in each bin interval and the crack width distribution (CWD) over the entire specimen surface at selected time stages between $t=1.5 \mathrm{~h}$ and $\mathrm{t}=25 \mathrm{~h}$. Mean values for three replicates $(A-C)$ are given

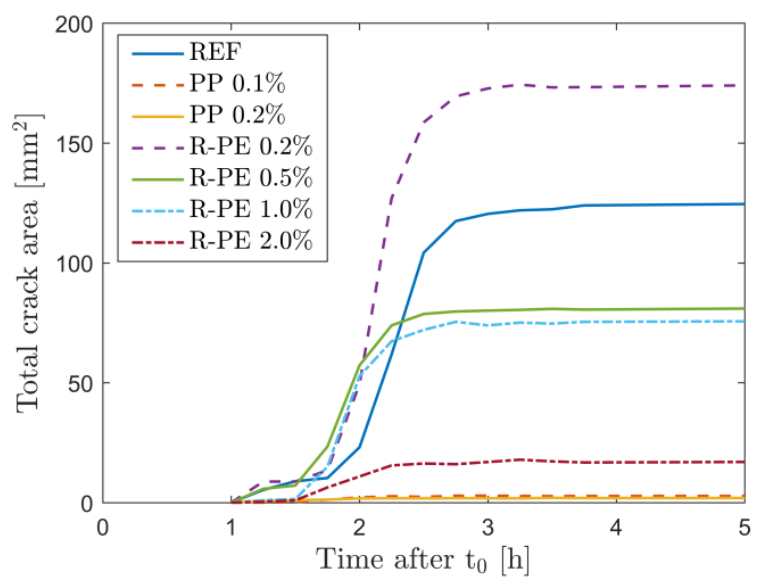

Fig. 12. Evolution in total crack area (TCA), mean values for three replicates (A-C) are given.

According to the CWD shown in Fig. 11, the specimens with the most severe surface cracking, REF and $0.2 \%$ R-PE and some very fine cracks had already initiated at $t=1.5 \mathrm{~h}$. The largest change with respect to initiation of surface cracking (given as total crack area per bin interval of crack widths) for these two specimen types occurred between the time stages $t=2.0 \mathrm{~h}$ and $t=2.25 \mathrm{~h}$. At $t=2.25 \mathrm{~h}$, the shape of the crack network as well as the shape of the CWD had formed and the further evolution in surface cracking was mainly because of propagating crack widths during the remaining test period until $t=25 \mathrm{~h}$. Regarding the CWD for the specimens with $0.5 \%$ and $1.0 \%$ of R-PE fibres, a similar behaviour as for the specimens with $0.2 \%$ R-PE fibres was seen until $t=2.0 \mathrm{~h}$, but after that the crack network and shape of CWD stabilized faster and did not increase to the same extent as the REF and $0.2 \%$ R-PE specimens, thus the fibres was shown to have an influence on the time and degree of surface cracking. This positive performance of the fibres was even more distinct for the specimens with R-PE fibre fractions of $2.0 \%$. From Fig. 12, it is seen that the final stabilization of the total crack area for the specimens REF and 02.\% R-PE happened at approximately $t=3.25 \mathrm{~h}$, while it had stabilized at approximately $\mathrm{t}=2.75 \mathrm{~h}$ for the specimens with $0.5 \%$ and $1.0 \%$ of R-PE fibres and at $t=2.25 \mathrm{~h}$ for the $2.0 \% \mathrm{R}-\mathrm{PE}$ specimens. The specimens with addition of 
commercial PP fibres performed best in controlling the surface cracking, and the cracking with respect to the total crack area for the PP $0.2 \%$ specimens had stabilized at $\mathrm{t}=2.25 \mathrm{~h}$.

\subsection{Free shrinkage behaviour analysed using DIC}

The surface displacement due to the plastic shrinkage of unrestrained mortar specimens that were allowed to deform freely was also monitored using the DIC technique simultaneous to the restrained shrinkage tests to investigate the influence of the fibre reinforcement on the free shrinkage behaviour. The displacement data obtained from the DIC software were used for further calculations in MATLAB, which made it possible to do a section-wise analysis of each individual section $\left(n_{i, s e c}\right)$ parallel to the axis as explained in Section 3.1.1 for the restrained shrinkage study. Most significant plastic shrinkage deformations took place in the $x$-direction (parallel to the length of the specimen) due to the specimen geometry and the direction of the wind exposure. The change in free shrinkage over time $(t=1-25 h)$ was calculated as the average of the maximum difference in displacement along each section $\left(n_{i, s e c}\right)$ from one end to the other taking the entire surface area into account. No surface cracking appeared on any of the free shrinkage specimens and it was observed that the sides of the specimens all easily detached from the sides of the moulds. Fig. 13a illustrates the in-plane free shrinkage strain in the $x$-direction $(\mathrm{mm} / \mathrm{m})$. The displacement (contraction) increased rapidly in the plastic phase until approximately $\mathrm{t}=2.5 \mathrm{~h}$ and then stabilized, thus some irregularities in the displacement data appeared over time. The graph shows that the largest in-plane free shrinkage strains over the length of the specimens were found for the specimens with $0.2 \%$ R-PE and the REF specimens, closely followed by the specimens with an addition of $0.5-1.0 \%$ of R-PE fibres and $0.1 \%$ of PP fibres. The specimens with an addition of $2.0 \%$ of R-PE fibres and $0.2 \%$ of PP fibres experienced the least horizontal shrinkage and performed similarly. 
442
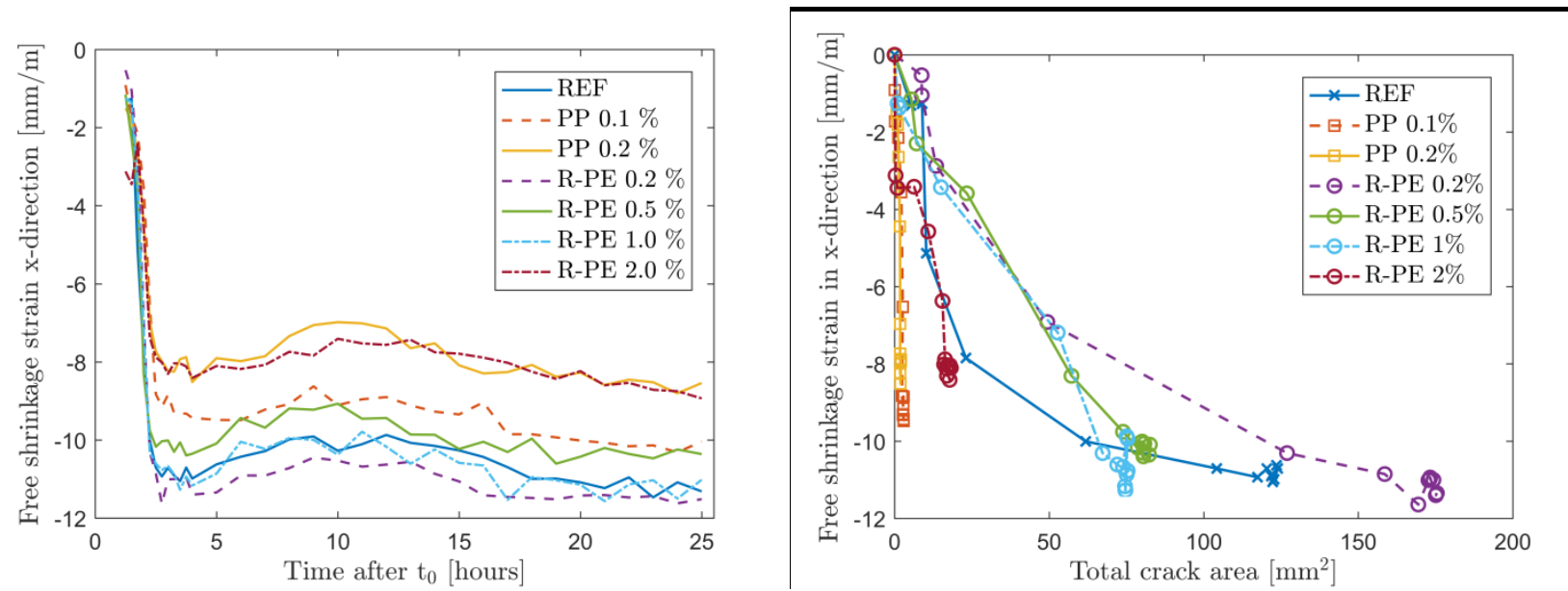

Fig. 13. a) In-plane free shrinkage strain in $x$-direction; b) In-plane free shrinkage strain in $x$-direction versus the total crack area of restrained shrinkage specimens. Mean values for three replicates $(A-C)$ are given

\subsubsection{Comparison of free and restrained shrinkage behaviour}

Fig. 13b shows the evolution of the total crack area on the restrained mortar overlays versus the free shrinkage strain of the unrestrained specimens. It is of interest to analyse whether the degree of free shrinkage correlates with the degree of restrained surface cracking. The variations in the free shrinkage behaviour between the different specimens were observed not to be significant compared to the variations in the total crack area of the restrained specimens with addition of varying fibre types and fractions. This is mainly due to the effect of the fibres because they have the ability to distribute the strains in the restrained overlays, which results in a reduced total crack area. A comparison of the specimens with $0.1 \%$ PP and $2.0 \%$ R-PE showed that even though the 2.0\% R-PE fibres had a larger influence on the free shrinkage, the total crack area was smaller for the $0.1 \%$ PP fibres. This again shows the superior ability of the commercially available PP fibres to distribute the strains in restrained mortar overlays.

\subsubsection{Fibre influence on workability of fresh mortar mixtures}

The workability of the fresh mortar mixtures with different fibre types and -fractions was evaluated based on the flow diameter and is shown in Fig. 14. The addition of fibres is clearly decreasing the flow diameter of the fresh mortars. As it was observed for the free shrinkage strain, the largest values were found for the 
REF specimens and the $0.2 \%$ R-PE specimens, with these two behaving similarly, followed by the $0.5 \%$ and 1.0\% R-PE specimens. For the PP fibres, an addition of only 0.1 vol\% was observed to influence the workability significantly; however, higher fibre fractions of R-PE fibres were necessary to obtain a similar effect. Mortars with an addition of 0.2 vol\% PP fibres and 2.0 vol\% R-PE fibres had similar workability.

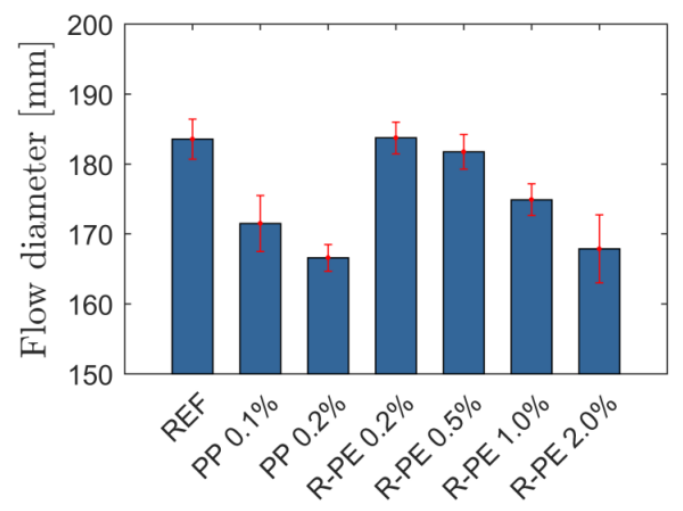

Fig. 14. Workability of fresh mortar mixtures by flow table test

\section{Conclusion}

A 2D-DIC technique was applied to study the formation of in-plane strains and displacements induced by plastic shrinkage of free and restrained mortar overlays under controlled environmental conditions with the aim of investigating the influence of the addition of two types of synthetic fibres. The two fibre types that were investigated were commercially available polypropylene (PP) fibres and recycled polyethylene (RPE) fibres obtained by mechanical cutting of discarded fishing nets. The fibre-reinforced mortar overlays were compared with an unreinforced reference mortar. An automated post-processing MATLAB routine enabled computation of basic crack parameters such as total crack area, maximum and mean crack width based on the DIC data. The evolution in total crack area during the test period of 1-25 $\mathrm{h}$ after casting was also analysed. The data was then presented in detailed histograms showing the relation between the total crack length/area within each bin interval and the crack width distribution over the entire specimen surface at various time stages.

From the results of the free and restrained shrinkage test series, the following conclusions were drawn: 
At the end of each test series, visible surface cracking appeared in some of the restrained mortar overlays. A more detailed visualization of the surface cracking was enabled by plotting the surface strain based on data obtained by DIC.

- The commercially available PP fibres were added to the fresh mixture in volume fractions of $0.1 \%$ and $0.2 \%$ and showed the best performance in controlling the restrained plastic shrinkage cracking. A crack reduction ratio (CRR) of 0.98 with respect to the total crack area was obtained for the specimens with PP fibres.

- The R-PE fibres were of a coarser nature than the PP fibres and, therefore, had to be added in higher volume fractions $(0.2-2.0 \%)$ to obtain results comparable to the PP fibres. The addition of 0.2\% R-PE fibres did not improve the performance with regard to the total crack area, even though a small improvement was expected. R-PE fibres added in a volume fraction of $2.0 \%$ showed a good performance in controlling plastic shrinkage cracking and a CRR of 0.85 with respect to the total crack area was obtained.

- The evolution in surface cracking over time was analysed by the crack width distribution at various time stages. This showed that the surface cracking on the specimens with addition of fibres stabilized faster than the specimens with most surface cracking, the REF specimens and the specimens with $0.2 \%$ of R-PE. The evolution in total crack area was also plotted over time, which showed that the plastic shrinkage cracking had stabilized between $t=2.25 \mathrm{~h}(\mathrm{PP} 0.2 \%)$ and $t=3.25$ h (Reference).

- The behaviour of free shrinkage specimens was also monitored and computed from DIC data. The smallest in-plane free shrinkage strain was found for the specimens with addition of $0.2 \%$ PP and 2.0\% R-PE. The largest free shrinkage appeared for the specimens with addition of $0.2 \%$ R-PE and for the reference specimen. The free shrinkage in all specimens initially increased rapidly, but stabilized at approximately $2.5 \mathrm{~h}$ after the start of mixing.

Based on these results it can be concluded that the DIC technique is a suitable tool for objectively studying the shrinkage behaviour of fresh cementitious materials. Furthermore, the R-PE fibres showed a good 

performance in controlling plastic shrinkage cracks in the retrained overlays when added in volume fraction of $2.0 \%$.

\section{Acknowledgement}

The study is part of the project Circular Ocean, which is funded through the ERDF Interreg VB Northern Periphery and Arctic (NPA) Programme 2014-2020 (Grant no. 21). The recycled polyethylene fibres were kindly provided by Plastix A/S.

\section{References}

[1] A. Bentur, S. Mindess, Fibre-Reinforced Cementitious Composites, 2nd Editio, Taylor \& Francis, 2006.

[2] P.N. Balaguru, S.P. Shah, Fiber Reinforced Cement Composites, McGraw-Hill, 1992.

[3] N. Banthia, R. Gupta, Influence of polypropylene fiber geometry on plastic shrinkage cracking in concrete, Cem. Concr. Res. 36.7 (2006) 1263-1267. doi:10.1016/j.cemconres.2006.01.010.

[4] J.H.J. Kim, C.G. Park, S.W. Lee, S.W. Lee, J.P. Won, Effects of the geometry of recycled PET fiber reinforcement on shrinkage cracking of cement-based composites, Compos. Part B Eng. 39.3 (2008) 442-450. doi:10.1016/j.compositesb.2007.05.001.

[5] P.J. Uno, Plastic Shrinkage Cracking and Evaporation Formulas, ACl Mater. J. 95.4 (1998) 365-375.

[6] N. Banthia, C. Yan, Shrinkage cracking in polyolefin fiber-reinforced concrete, ACl Mater. J. 97.4 (2000) 432-437.

[7] N. Banthia, R. Gupta, Test Method for Evaluation of Plastic Shrinkage Cracking in Fiber-Reinforced Cementitious Materials, Exp. Tech. 31.6 (2007) 44-48. doi:10.1111/j.1747-1567.2007.00191.x.

[8] T. Mauroux, F. Benboudjema, P. Turcry, A. Aït-Mokhtar, O. Deves, Study of cracking due to drying in coating mortars by digital image correlation, Cem. Concr. Res. 42.7 (2012) 1014-1023. doi:10.1016/j.cemconres.2012.04.002. 
532 [9] A.E. Naaman, T. Wongtanakitcharoen, G. Hauser, Influence of different fibers on plastic shrinkage cracking of concrete, ACI Mater. J. 102.1 (2005) 49-58.

534 [10] J. Branston, S. Das, S.Y. Kenno, C. Taylor, Influence of basalt fibres on free and restrained plastic shrinkage, Cem. Concr. Compos. 74 (2016) 182-190. doi:10.1016/j.cemconcomp.2016.10.004.

[11] C.A. Juarez, G. Fajardo, S. Monroy, A. Duran-Herrera, P. Valdez, C. Magniont, Comparative study between natural and PVA fibers to reduce plastic shrinkage cracking in cement-based composite,

[13] I.M.G. Bertelsen, C. Kragh, G. Cardinaud, L.M. Ottosen, G. Fischer, Quantification of plastic shrinkage cracking in mortars using digital image correlation, Submitt. 2018.04.28. (n.d.).

[16] C. Qi, J. Weiss, J. Olek, Characterization of plastic shrinkage cracking in fiber reinforced concrete

[18] V. Dey, R. Kachala, A. Bonakdar, N. Neithalath, B. Mobasher, Quantitative 2D Restrained Shrinkage 
558 [19] M.A. Sutton, J.J. Orteu, H. Schreier, Image correlation for shape, motion and deformation measurements: basic concepts, theory and applications, Springer Science \& Business Media, 2009.

[20] A. Messan, P. lenny, D. Nectoux, Free and restrained early-age shrinkage of mortar: Influence of glass fiber, cellulose ether and EVA (ethylene-vinyl acetate), Cem. Concr. Compos. 33.3 (2011) 402410. doi:10.1016/j.cemconcomp.2010.10.019.

[21] P. Zhao, Master thesis. Digital Image Correlation to Evaluate Plastic Shrinkage Cracking in CementBased Materials, Concordia University, Montreal, Canada, 2016.

[22] S. Ghourchian, M. Wyrzykowski, L. Baquerizo, P. Lura, Susceptibility of Portland cement and blended cement concretes to plastic shrinkage cracking, Cem. Concr. Compos. 85 (2018) 44-55. doi:10.1016/j.cemconcomp.2017.10.002.

[23] M. Némoz-Gaillard, D. Nectoux, E. Dallies, D. Muller, Influence of AR glass fibers on the cracking of concrete : analysis at the very early age by digital image correlation, in: PRO 23 Int. RILEM Conf. Early Age Crack. Cem. Syst., 2002: pp. 237-244.

[24] E.D. Dzaye, G. De Schutter, D. Aggelis, Application of Digital Image Correlation to Cement Paste, in: Proceedings. Eighteenth Int. Conf. Exp. Mech., 2018. doi:10.3390/ICEM18-05332.

[25] P. Soroushian, F. Mirza, A. Alhozaimy, Plastic Shrinkage cracking of Polypropylene fiber-reinforced concrete, ACl Mater. J. 92.5 (1995) 553-560.

[26] P. Balaguru, Contribution of fibers to crack reduction of cement composites during the initial and final setting period, ACI Mater. J. 91.3 (1994) 280-288.

[27] E. Boghossian, L.D. Wegner, Use of flax fibres to reduce plastic shrinkage cracking in concrete, Cem. Concr. Compos. 30.10 (2008) 929-937. doi:10.1016/j.cemconcomp.2008.09.003.

[28] R.P. Borg, O. Baldacchino, L. Ferrara, Early age performance and mechanical characteristics of recycled PET fibre reinforced concrete, Constr. Build. Mater. 108 (2016) 29-47. doi:10.1016/j.conbuildmat.2016.01.029. 
[29] N. Pešić, S. Živanović, R. Garcia, P. Papastergiou, Mechanical properties of concrete reinforced with recycled HDPE plastic fibres, Constr. Build. Mater. 115 (2016) 362-370. doi:10.1016/j.conbuildmat.2016.04.050.

[30] A. Sivakumar, M. Santhanam, A quantitative study on the plastic shrinkage cracking in high strength hybrid fibre reinforced concrete, Cem. Concr. Compos. 29.7 (2007) 575-581. doi:10.1016/j.cemconcomp.2007.03.005.

[31] H. Najm, P. Balaguru, Effect of large-diameter polymeric fibers on shrinkage cracking of cement composites, ACI Mater. J. 99.4 (2002) 345-351.

[32] B.S. Al-Tulaian, M.J. Al-Shannag, A.R. Al-Hozaimy, Recycled plastic waste fibers for reinforcing Portland cement mortar, Constr. Build. Mater. 127 (2016) 102-110. doi:10.1016/j.conbuildmat.2016.09.131.

[33] M. Serdar, A. Baričević, M. Jelčić Rukavina, M. Pezer, D. Bjegović, N. Štirmer, Shrinkage Behaviour of Fibre Reinforced Concrete with Recycled Tyre Polymer Fibres, Int. J. Polym. Sci. 2015.3 (2015) 1-9. doi:10.1155/2015/145918.

[34] F.L. Auchey, The Use of Recycled Polymer Fibers as Secondary Reinforcement in Concrete Structures, J. Constr. Educ. 3.2 (1998) 131-140.

[35] L. Gu, T. Ozbakkaloglu, Use of recycled plastics in concrete: A critical review, Waste Manag. 51 (2016) 19-42. doi:10.1016/j.wasman.2016.03.005.

[36] R. Siddique, J. Khatib, I. Kaur, Use of recycled plastic in concrete: A review, Waste Manag. 28.10 (2008) 1835-1852. doi:10.1016/j.wasman.2007.09.011.

[37] C.J. Moore, Synthetic polymers in the marine environment: A rapidly increasing, long-term threat, Environ. Res. 108 (2008) 131-139. doi:10.1016/j.envres.2008.07.025.

[38] S. Spadea, I. Farina, A. Carrafiello, F. Fraternali, Recycled nylon fibers as cement mortar reinforcement, Constr. Build. Mater. 80 (2015) 200-209. doi:10.1016/j.conbuildmat.2015.01.075.

[39] S. Orasutthikul, D. Unno, H. Yokota, Effectiveness of recycled nylon fiber from waste fishing net with 
respect to fiber reinforced mortar, Constr. Build. Mater. 146 (2017) 594-602. doi:10.1016/j.conbuildmat.2017.04.134.

[40] I.M.G. Bertelsen, L.M. Ottosen, Recycling of waste PE fishing nets as fibre reinforcement in gypsumbased composites, Submitted. (n.d.).

[41] Ö. Eren, K. Marar, Effect of steel fibers on plastic shrinkage cracking of normal and high strength concretes, Mater. Res. 13 (2010) 135-141. doi:10.1590/S1516-14392010000200004.

[42] W.P. Boshoff, C.J. Adendorff, Effect of sustained tensile loading on SHCC crack widths, Cem. Concr. Compos. 37 (2013) 119-125. doi:10.1016/j.cemconcomp.2012.11.009.

[43] F. Lagier, X. Jourdain, C. De Sa, F. Benboudjema, J.B. Colliat, Numerical strategies for prediction of drying cracks in heterogeneous materials: Comparison upon experimental results, Eng. Struct. 33.3 (2011) 920-931. doi:10.1016/j.engstruct.2010.12.013.

[44] R. Ranade, J. Zhang, J.P. Lynch, V.C. Li, Influence of micro-cracking on the composite resistivity of Engineered Cementitious Composites, Cem. Concr. Res. $58 \quad$ (2014) 1-12. doi:10.1016/j.cemconres.2014.01.002.

[45] N. Yousefieh, A. Joshaghani, E. Hajibandeh, M. Shekarchi, Influence of fibers on drying shrinkage in restrained concrete, $\quad$ Constr. Build. $\quad$ Mater. $148 \quad$ (2017) 833-845. doi:10.1016/j.conbuildmat.2017.05.093.

[46] T.U. Mohammed, N. Otsuki, M. Hisada, T. Shibata, Effect of Crack Width and Bar Types on Corrosion of Steel in Concrete, J. Mater. Civ. Eng. 13.3 (2001) 194-201. doi:10.1061/(ASCE)08991561(2001)13:3(194). 